\title{
Horizons in Physics Education: a network to improve the attraction of physics
}

\author{
Nadine Witkowski* \\ Université Pierre et Marie Curie \\ E-mail: nadine.witkowski@upmc.fr
}

\begin{abstract}
The academic network HOPE - Horizons of Physics Education - has been launched for three years from October 2013 with the support of the Life Long Learning Programme of the European Union. The 71 full partners are from 31 LLP-eligible countries of the Europea; they comprise 65 academic partners and 6 non-academic partners including the European Physical Society. The consortium is further enriched by 20 associated partners including the Institute of Physics, the American Physical Society or GIREP.

With an overall aim of enhancing the impact of physics within Europe and its visibility in society, the network will research and share good practice within four themes: the factors influencing young people to choose to study physics; physics graduates' competences that enable them to contribute to the new needs of the European economy and society; the effectiveness and attractiveness of physics teaching in Europe's university physics departments and their competitiveness in the global student market; strategies for increasing the supply of well-trained physics school teachers and for developing links between university physics departments and the teaching of physics in schools.
\end{abstract}

Frontiers of Fundamental Physics 14 - FFP14,

15-18 July 2014

Aix Marseille University (AMU) Saint-Charles Campus, Marseille

\footnotetext{
*Speaker.
} 